UDC 539.3

S. I. Trubachev, O. N. Alekseychuk

\title{
THE OSCILLATIONS OF ROD CONSTRUCTIONS WITH TAKING INTO ACCOUNT THE ENERGY DISSIPATION
}

\section{Introduction}

The rod systems and rods, structural elements are widely used in aircraft. During the exploitation they are exposed to vibration loads, therefore the researching of dynamic characteristics of the rods is an actual problem of vibration strength.

In studying of the dissipation of the internal energy in the materials the one of the complicated problems is the problem when the material is acting by a variable load. If the frequency of the exciting loads has definite ratios with the eigenfrequency of oscillations, the level of dynamic loads is sharply increases.

The dissipative properties are important in these materials. The appropriate models are created according on the dissipation mechanism of the mechanical energy.

\section{The problem's statement and solving}

Let us consider the bending vibrations of the rod taking into account the energy dissipation, which are described by the equation [1]:

$$
\frac{\partial^{2}}{\partial t^{2}}\left(E I \frac{\partial^{2} W}{\partial z^{2}}\right)+m \frac{\partial^{2} W}{\partial t^{2}}=\varepsilon f\left(W, \frac{\partial W}{\partial t}\right)+\varepsilon q(z) \cos p t ;
$$

where $E$ is the modulus of elasticity, $I$ - is the moment of inertia of the rod elatively central axis, $\mathrm{m}$-is the mass per unit length, $f-$ is a function of the dissipation energy, $q-$ is the intensity of the disturbing load, $p$ is he frequency of the external excitation, $\varepsilon-$ a small parameter.

$Z$ - axis is directed along the rod. We choosed the Navier condition as a boundary conditions. The solution of the differential equation (1), at $q(z)=0$, which corresponds to free vibration can be written as

$$
\begin{gathered}
W(z, t)=W(z) a \cos \tau ; \\
\tau=\omega_{0} t+\psi ;
\end{gathered}
$$

where $W(z)$ and $\omega_{\mathrm{o}}$ are the waveform and the corresponding frequency, which are defined by the equation (1) with $\varepsilon=0$ (free oscillations of the rod considering energy dissipation), $a$ and $\tau$ - are the amplitude and the phase of the oscillations that are satisfying the conditions of the first approximation [1]: 


$$
\left\{\begin{array}{l}
\frac{d a}{d t}=\varepsilon A_{1}(a) \\
\frac{d \tau}{d t}=\omega_{0}+\varepsilon B_{1}(a)=\omega(a) .
\end{array}\right.
$$

The coefficients of the equations (3) are defined as

$$
\begin{gathered}
A_{1}(a)=-\frac{1}{2 \pi M \omega_{0}} \int_{0}^{l} \int_{0}^{2 \pi} f_{0}\left(W, \frac{\partial W}{\partial t}\right) W(z) \sin \tau d z d \tau \\
B_{1}=-\frac{1}{2 \pi M \omega_{0} a} \int_{0}^{l} \int_{0}^{2 \pi} f_{0}\left(W, \frac{\partial W}{\partial t}\right) W(z) \cos \tau d z d \tau,
\end{gathered}
$$

where $M=\int_{0}^{l} m W^{2}(z) d z$.

$f_{o}-$ is the function of energy dissipation.

We define the relationship between the logarithmic decrement function and energy dissipation.

$$
\Lambda=\ln \frac{a_{n}}{a_{n+1}} .
$$

For weak damping we have

$$
\Lambda=-\frac{\Delta a}{a} .
$$

Taking the time increment $\Delta t$ equal to the period the oscillations, we find the amplitude of the increment for the period $T=\frac{2 \pi}{\omega}$

$$
\Delta a=\frac{d a}{d t} \Delta t=\frac{d a}{d t} \frac{2 \pi}{\omega} .
$$

Taking into account (7), the expression (6) for the logarithmic decrement of the amplitude can be written as:

$$
\Lambda=-\frac{2 \pi}{\omega a} \frac{d a}{d t}
$$

but $\frac{d a}{d t}=\varepsilon A_{1}(a)$, than

$$
A_{1}(a)=-\frac{\omega a}{2 \pi} \Lambda .
$$

Let us examine the expression

$$
\Lambda_{1}=\ln \frac{\omega_{n}}{\omega_{n+1}} .
$$


Then, for weak damping

$$
\Lambda_{1}=\frac{\Delta \omega}{\omega} .
$$

Since the change in frequency $\Delta \omega$ during the period $T=\Delta t=\frac{2 \pi}{\omega} ;$ is equal to

$$
\Delta \omega=\frac{d \omega}{d t} \Delta t=\frac{2 \pi}{\omega} \frac{d \omega}{d t}
$$

then the expression (11) takes the form

$$
\Lambda_{1}=\frac{2 \pi}{\omega^{2}} \frac{d \omega}{d t} .
$$

Let us differentiate the second equation (3) with respect to time and obtain

$$
\frac{d \omega(a)}{d t}=\frac{d B_{1}}{d a} \frac{d a}{d t}
$$

By substituting (14) into (15) we obtain

$$
\Lambda_{1}=\frac{2 \pi}{\omega} \frac{d B_{1}}{d a} \frac{d a}{d t} .
$$

Or are considering (8)

$$
\Lambda_{1}=-\frac{a}{\omega} \Lambda \frac{d B_{1}}{d a}
$$

whence

$$
B_{1}(a)=-\int_{0}^{a} \frac{\Lambda_{1} \omega}{\Lambda a} d a
$$

Thus the coefficients $A_{1}(\alpha) \ldots B_{1}(\alpha)$ of the first approximation equations (4) can be expressed in terms of the values $\square_{1}$ and $\square$, which are depends on the amplitude and frequency of the oscillations. These values can be obtained from an experiment on vibrogram of the damped oscillations.

Let us consider the forced vibrations of the rod. A particular solution of the equation (1) with the right side $(q \neq 0)$ has the form in a first approximation:

$$
W(z, t)=W(z) a \cos \tau, \quad \tau=p t+\varphi .
$$

Where the amplitude $\alpha$ and phase angle $\varphi$ are determined from the equations

$$
\begin{gathered}
\frac{d a}{d t}=A_{1}(a)-\frac{A}{\left(\omega_{0}+p\right) M} \sin \varphi \\
\frac{d \varphi}{d t}=\omega_{0}-p+B_{1}(a)-\frac{A}{a M\left(\omega_{0}+p\right)} \cos \varphi
\end{gathered}
$$




$$
A=\int_{0}^{l} q(z) W(z) d z .
$$

The coefficients $A_{1}(\alpha)$ and $B_{1}(\alpha)$ of the first approximation equations (19) are calculated by the formulas (9) and (17). With the stationary oscillations, equation (19) becomes

$$
\left\{\begin{array}{l}
\frac{p^{2}}{\omega_{0}^{2}}=1-\frac{A}{a M \omega_{0}^{2}}\left(\cos \psi-\frac{B_{1} a}{A_{1}} \sin \varphi\right) \\
\sin \varphi=\frac{2 \omega_{0} M A_{1}}{A} .
\end{array}\right.
$$

According to equation (20) it is easy to construct the resonance curve. If it possible to ignore the influence of the energy dissipation on the natural frequency (elliptical hysteresis loop), then in equations (18), (19) and (20) we must take $\mathrm{B}_{1}=0 ; \omega=\omega_{0}$.

When we solving problems for rod constructions the greatest interest has the spectrum of the natural frequencies and corresponding mode shapes. It is proposed to use a two-node finite element in the case of plane bending vibrations of the rod. In this case, the nodal unknowns are deflections and turning angles the nodes. For the approximation of displacements we use a thirdorder polynomial:

$$
\mathcal{w}_{x}=\mathcal{w}_{i} \frac{1}{l^{3^{3}}}\left(2 x^{3}-3 x^{2} l+l^{3}\right)+\mathcal{W}_{j} \frac{1}{l^{3}}\left(3 x^{2} l-2 x^{3}\right)+\varphi_{i} \frac{1}{l^{2}}\left(x l^{2}-2 x^{2} l+x^{3}\right)+\varphi_{j} \frac{1}{l^{3}}\left(x^{3}-l x^{2}\right) .
$$

To find the spectrum eigenfrequencies and mode shapes is suggested to use a method of increasing stiffness [2], which is based on the minimization of functionals of the Rayleigh type. The method coordinatewise descent is applied to solve the problem of minimizing the functional [3], which is one of the methods of nonlinear programming. It should be noted that the combination of increased stiffness method and the method coordinatewise descent, has allowed to create efficient computer algorithm/

\section{Conclusions}

We investigated the fluctuations rod structures based on energy dissipation on the basis of an expansion in the small parameter. The obtained solutions allow constructing the amplitude-frequency characteristics for oscillations. It was demonstrated the using of the logarithmic decrement for solving the problem of forced oscillations with the nonlinearity. A numerical calculation of the oscillation rod structures on the basis of a two-level finite element was represented.

\section{References}


1. Василенко М. В. Теорія коливань і стійкості руху // М. В. Василенко, О. М. Алексейчук /- К.: Вища школа, 2004. - 525 с.

1. Бабенко A. E. Определение частотного спектра и собственных форм колебаний упругих систем методом повышения жесткостей // А. Е. Бабенко, О. А. Боронко, Н. В. Василенко, С. И. Трубачев/ Проблемы прочности. - 1990. - № 2 - с. 122-124.

2. Бабенко A. E. Применение и развитие метода покоординатного спуска в задачах определения напряженно-деформированного состояния при статических и вибрационных нагрузках // А. Е. Бабенко, Н. И. Бобырь, С. Л. Бойко, О. А. Боронко / - К.: Инрес, 2005. - 264 с. 